records; Antonella Germani for reviewing the clinical records; Bruno Caffari, Marina Maggini, Alfonso Mele, Roberto Raschetti, Stefania Spila Alegiani, Tommaso Stroffolini, Nicola Vanacore (Istituto Superiore di Sanità), Achille Caputi (University of Messina), and Albano Del Favero (University of Perugia) who participated in the discussion and review of the study protocol and the study findings; and Sara Modigliani for editorial support.

Contributors: All authors contributed to designing the study, interpreting the results, and writing the paper. GT will act as guarantor for the paper.

Funding: Expenses were covered by NHS funds. The study was partly supported by research funds from the Ministry of Health and the Umbria Regional Health Authority.

Competing interests: None declared.

1 National Agency for Medicine (Finland). www.nam.fi/english/news/ press_releases/nimed.html (accessed 16 June 2003).

Agencia Espanola del Medicamento. www.msc.es/agemed/csmh/notas/ nimesulida asp (accessed 16 June 2003).

Macia MA, Carvajal A, Garcia del Pozo J, Vera E, del Pino A. Hepatotoxicity associated with nimesulide: data from the Spanish pharmacovigilance system Clin Pharmacol Ther 2002·79:596-7.

4 Conforti A, Leone R, Moretti U, Mozzo F, Velo G. Adverse drug reactions related to the use of NSAIDs with a focus on nimesulide. Results from spontaneous reporting from a northern Italian area. Drug Safet 2001;24:1081-90

Agence Francaise de Securité Sanitaire des Produits de Santé agmed.sante.gouv.fr (accessed 16 June 2003).

International Consensus Meeting. Criteria of drug-induced liver disorders. J Epatol 1990;11:272-6.
7 Danan G. Liver test abnormalities. In: Bénichou C, ed. Adverse drug reactions. A practical guide to diagnosis and management. Chichester: Wiley, 1994 Danan G, Bénichou C. Causality assessment of adverse reactions to drugs: I. A novel method based on the conclusions of international consensus meetings: application to drug-induced liver injuries. J Clin Epidemiol 1993;46:1323-30.

9 García-Rodríguez LA, Pérez Gutthann S, Walker AM, Lueck L. The role of non-steroidal anti-inflammatory drugs in acute liver injury. $B M J$ 1992;305:865-8.

10 García-Rodríguez LA, Williams R, Derby LE, Dean AD, Jick H. Acute liver injury associated with nonsteroidal anti-inflammatory drugs and the role of risk factors. Arch Intern Med 1994:154.311-6.

11 Walker AM. Quantitative studies of the risk of serious hepatic injury in persons using nonsteroidal antiinflammatory drugs. Arthritis Rheum 1997:40:201-8.

12 Hernandez-Diaz S, García-Rodríguez LA. Epidemiologic assessment of the safety of conventional nonsteroidal anti-inflammatory drugs. $A m \mathrm{~J}$ Med 2001;110:20-7S

13 Hernandez-Diaz S, García-Rodríguez LA. Association between nonsteroidal anti-inflammatory drugs and upper gastrointestinal tract bleeding/ perforation. An overview of epidemiologic studies published in the 1990s. Arch Intern Med 2000;160:2093-9.

14 García-Rodríguez LA, Cattaruzzi G, Troncon MG, Agostinis L Risk of hospitalisation for upper gastrointestinal tract bleeding associated with kespitalicin nists, and or a

15 Menniti-Ippolito F, Maggini M, Raschetti R, Da Cas R, Traversa G, Walker AM. Ketorolac use in outpatients and gastrointestinal hospitalization: a comparison with other non-steroidal anti-inflammatory drugs in Italy. Eur J Clin Pharmacol 1998;54:393-7.

16 Traversa G, Walker AM, Menniti-Ippolito F, Caffari B, Capurso L, Dezi A, et al. Gastroduodenal toxicity of different NSAIDs: a case-control study in the province of Rome. Epidemiology 1995;6:49-54.

(Accepted 16 June 2003)

\title{
Prospective observational cohort study of time saved by prehospital thrombolysis for ST elevation myocardial infarction delivered by paramedics
}

David K Pedley, Kim Bissett, Elizabeth M Connolly, Carol G Goodman, Ian Golding, T H Pringle, G P McNeill, S D Pringle, M C Jones

Ninewells Hospital and Medical School, Dundee DD1 9SY David K Pedley specialist registrar accident and emergency

Kim Bissett audit nurse, chest pain service

Elizabeth M

Connolly

nurse practitioner,

chest pain service

Carol G Goodman

clinical group

manager, medicine

and cardiovascula

group

T H Pringle

consultant

cardiologist

G P McNeill

consultant

cardiologist

S D Pringle

consultant

cardiologist

M C Jones

consultant in acut

medicine

continued over

BMJ 2003;327:22-6

\section{Abstract}

Objectives To evaluate a system of prehospital thrombolysis, delivered by paramedics, in meeting the national service framework's targets for the management of acute myocardial infarction. Design Prospective observational cohort study comparing patients with suspected acute myocardial infarction considered for thrombolysis in the prehospital environment with patients treated in hospital.

Setting The catchment area of a large teaching hospital, including urban and rural areas. Participants 201 patients presenting concurrently over a 12 month period who had changes to the electrocardiogram that were diagnostic of acute myocardial infarction or who received thrombolysis for suspected acute myocardial infarction.

Main outcome measures Time from first medical contact to initiation of thrombolysis (call to needle time), number of patients given thrombolysis appropriately, and all cause mortality in hospital. Results The median call to needle time for patients treated before arriving in hospital $(\mathrm{n}=28)$ was $52(95 \%$ confidence interval 41 to 62) minutes. Patients from similar rural areas who were treated in hospital $(n=43)$ had a median time of 125 (104 to 140) minutes. This represents a median time saved of 73 minutes $(\mathrm{P}<0.001)$. Sixty minutes after medical contact $64 \%$ of patients $(18 / 28)$ treated before arrival in hospital had received thrombolysis; this compares with $4 \%$ of patients $(2 / 43)$ in a cohort from similar areas. Median call to needle time for patients from urban areas $(\mathrm{n}=107)$ was 80 (78 to 93$)$ minutes. Myocardial infarction was confirmed in $89 \%$ of patients $(25 / 28)$ who had received prehospital thrombolysis; this compares with $92 \%(138 / 150)$ in the two groups of patients receiving thrombolysis in hospital.

Conclusions Thrombolysis delivered by paramedics with support from the base hospital can meet the national targets for early thrombolysis. The system has been shown to work well and can be introduced without delay.

\section{Introduction}

Evidence of the benefits of early thrombolysis in the context of an acute myocardial infarction is overwhelming. ${ }^{1234}$ This is reflected in the national service framework for coronary heart disease in the adoption of a challenging standard "call to needle time" (from the initial call for help to treatment) of less than 60 minutes. $^{5}$ 
In urban areas it may be possible to meet these targets by rapid transfer and early administration of thrombolytic agents in hospital. In rural communities, however, where transfer times are often in excess of 30 minutes, the national service framework document acknowledges that other models of care-for example, prehospital thrombolysis-might represent the only access to early treatment. ${ }^{5}$

In our region of Scotland the closure of the coronary care facility of a small district general hospital as part of a review of acute services led us to explore prehospital thrombolysis as a strategy to meet the needs of a group of patients now exposed to longer journey times. We describe a system of prehospital thrombolysis delivered by paramedics in ambulances, with clinical decision support provided by the emergency medicine department of the base hospital via a mobile telemetry link.

\section{Practitioners, patients, and methods}

\section{Establishing a system of prehospital thrombolysis} In determining the area that the prehospital thrombolysis service should cover we considered travelling times to the teaching hospital from the area previously served by the district general hospital. The area where the time to reach hospital was to be increased notably was thought to be critical. We designated this as the study area and for convenience defined it as postcode regions DD10 and DD11. Patients reporting symptoms suggestive of an acute myocardial infarction from within this area were to be considered for prehospital thrombolysis. In cooperation with the Scottish Ambulance Service a cohort of experienced paramedics based in ambulance stations in this area were given additional training in the presentation and management of acute myocardial infarction. In addition a clinical placement was arranged for them in the accident and emergency department. To allow the intravenous administration of opiate analgesia and thrombolysis by paramedics, the Scottish Ambulance Service sought a local patient group directive. We selected tenecteplase as the thrombolytic of choice as we considered its single bolus administration ideal for prehospital use. The drug was used in accordance with the manufacturer's current protocols. Ambulances were fitted with telemetry equipment (Ortivus Mobimed M300), which uses mobile phone technology to allow transmission of data from a 12 lead electrocardiogram.

\section{Inclusion and exclusion criteria}

We considered patients in the study area who presented with chest pain and diagnostic changes on their electrocardiogram and who had no contraindications as eligible for prehospital thrombolysis. In accordance with the second international study of infarct survival (ISIS 2) ${ }^{2}$ we judged criteria of the electrocardiogram to be present or absent. After communication between senior medical staff in the accident and emergency department and the paramedic on the scene, a treatment decision was then reached. We applied a standardised list of criteria to each presentation, a positive response to each question required before thrombolysis (box). The final decision to administer thrombolysis lay with the paramedic.

\section{Criteria that have to be met before thrombolysis can be initiated}

A positive response is required to each question before thrombolysis is undertaken. (a) Is the patient conscious and oriented for time, place, and person? (b) Has the patient had typical symptoms of a myocardial infarction? (c) Did the pain build up gradually rather than starting abruptly?

(d) Did the continuous symptoms start less than six hours ago?

(e) Can you confirm that breathing does not influence the severity of the pain?

(f) Is the patient unlikely to be pregnant?

(g) Can you confirm the patient has not had a miscarriage or given birth in the past two weeks?

(h) If the patient has ever suffered from a peptic ulcer, can you confirm that he or she has been free of symptoms for the past six months?

(i) Has the patient been free from any major neurological problems such as stroke, head injury requiring hospital admission, spinal operations, brain cancer, or aneurysms?

(j) Is the patient free from any bleeding tendency or recent (less than two weeks) blood loss (other than menstruation)?

(k) Can you confirm that the patient is not taking warfarin?

(l) Can you confirm the patient has remained free from any trauma in the past two weeks, or any major surgical procedure in the past two months?

( $m$ ) Can you confirm that the patient's blood pressure is less than $180 / 120$ (either value)?

\section{Data collection}

For each patient presenting to the base hospital with a diagnosis of acute myocardial infarction we recorded the times of onset of symptoms, first call for professional help, and arrival of general practitioner and ambulance, arrival at hospital, and start of thrombolytic treatment. We also recorded the time spent on the scene. We reviewed case notes for each patient retrospectively to determine the diagnosis at discharge. The study took place in the 12 months from 6 December 2001 to 6 December 2002.

We divided patients into three concurrent groups. Group 1 consisted of patients presenting within a radius of approximately $15 \mathrm{~km}$ of the hospital (postcodes DD1 to DD6), who were considered for thrombolysis in hospital in the conventional way. Group 2 included patients presenting outside a $15 \mathrm{~km}$ radius of the base hospital, who were considered for

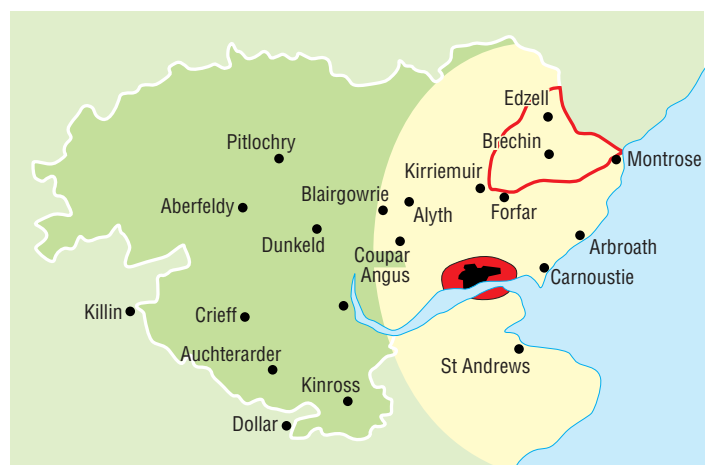

Patients presenting with chest pain from urban areas (post codes DD1-DD6) Patients presenting with chest pain from rural areas who would normally be transferred to Ninewells Hospital

Tayside region

Fig 1 Approximate catchment area for "chest pain" referrals to Ninewells Hospital in Dundee, Scotland. The "urban" group refers to patients from postcodes DD1 to DD6. The "study area" is outlined in red and refers to postcodes DD10 and DD11
Scottish Ambulance DD3 8PQ

Ian Golding divisional officer Correspondence to: D K Pedley david.pedley@ tuht.scot.nhs.uk Service, Dundee 


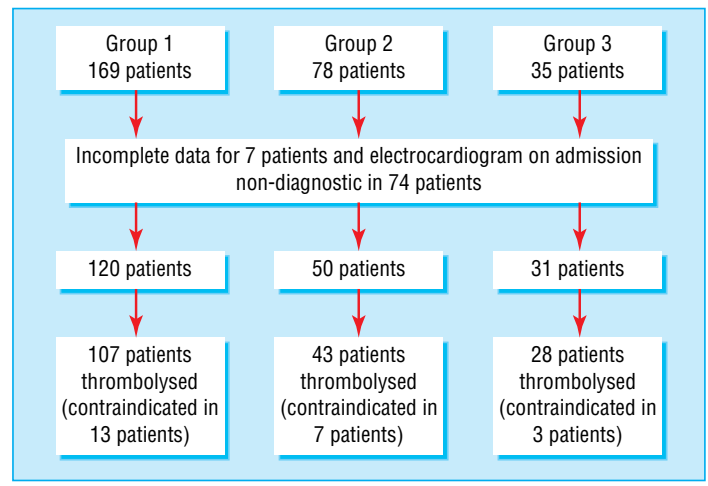

Fig 2 Patients with diagnosis of ST elevation myocardial infarction included in the study ( $\mathrm{n}=282$ ). Group 1 refers to patients within the "urban" area. Group 2 refers to patients from rural areas who were considered for thrombolysis in hospital. Group 3 refers to patients from the study area who were considered for prehospital thrombolysis

conventional thrombolysis in hospital. Group 3 included patients presenting outside a $15 \mathrm{~km}$ radius of the base hospital and in the area previously served by the district general hospital (postcodes DD10 and DD11); these patients were considered for prehospital thrombolysis. Figure 1 shows the approximate catchment area of the base hospital.

\section{Diagnostic definitions}

A retrospective review of case notes allowed us to ascribe a discharge diagnosis to each patient. We recorded a definite myocardial infarction when we found a convincing history plus ST segment elevation on the electrocardiogram and a rise in biochemical markers such as creatine kinase or in equivocal cases a troponin $\mathrm{T}$ concentration above the reference range. This was in keeping with standard clinical practice.

Time delays (in minutes) for groups of patients receiving in-hospital and prehospital thrombolysis in the catchment area of Ninewells Hospital in Dundee, Scotland. Median times do not sum arithmetically

\begin{tabular}{|c|c|c|c|}
\hline & Group $1(n=107)^{*}$ & Group $2(n=43) \dagger$ & Group $3(n=28) \ddagger$ \\
\hline \multicolumn{4}{|l|}{ Response time } \\
\hline Median (mean) & $11(25)$ & $14(28)$ & $20(27)$ \\
\hline Interquartile range & $7-30$ & $8-37$ & $7-41$ \\
\hline $95 \% \mathrm{Cl}$ & 19 to 32 & 19 to 37 & 19 to 36 \\
\hline \multicolumn{4}{|l|}{ On scene time } \\
\hline Median (mean) & $14(15)$ & $15(18)$ & $25(29)$ \\
\hline Interquartile range & $10-19$ & $11-22$ & $20-37$ \\
\hline $95 \% \mathrm{Cl}$ & 13 to 16 & 16 to 21 & 24 to 35 \\
\hline \multicolumn{4}{|l|}{ Transfer time } \\
\hline Median (mean) & $13(14)$ & $31(37)$ & $41(44)$ \\
\hline Interquartile range & 8-17 & $27-38$ & $33-55$ \\
\hline $95 \% \mathrm{Cl}$ & 13 to 16 & 33 to 41 & 38 to 50 \\
\hline \multicolumn{4}{|l|}{ Door to needle time } \\
\hline Median (mean) & $30(39)$ & $27(36)$ & $\mathrm{N} / \mathrm{A}$ \\
\hline Interquartile range & $20-50$ & $21-50$ & \\
\hline $95 \% \mathrm{Cl}$ & 33 to 45 & 27 to 44 & \\
\hline \multicolumn{4}{|l|}{ Call to needle time } \\
\hline Median (mean) & $80(86)$ & 125 (122) & $52(51)$ \\
\hline Interquartile range & $62-110$ & $88-155$ & $39-71$ \\
\hline $95 \% \mathrm{Cl}$ & 78 to 93 & 104 to 140 & 41 to 62 \\
\hline
\end{tabular}

*Urban and suburban patients receiving in-hospital care.

tRural patients receiving in-hospital care.

$\ddagger$ Łural patients receiving prehospital care.

\section{Results}

Two hundred and eighty two patients were admitted to the base hospital with a diagnosis of ST elevation myocardial infarction, or received thrombolysis for a suspected acute myocardial infarction over the study period. Two hundred and one patients had diagnostic changes of the electrocardiogram at presentation. Of these, 178 patients received thrombolytic agents and were selected for further analysis. Figure 2 shows the breakdown of patients' groups. Myocardial infarction was confirmed in $89 \%$ of patients $(25 / 28)$ who received thrombolysis before arriving at the hospital; this compares with $92 \%(138 / 150)$ in the groups receiving thrombolysis in hospital. All cause mortality in hospital was $11 \%(3 / 28)$ in the prehospital group, compared with $12 \%$ of patients $(5 / 43)$ in the cohort from rural areas who were treated in hospital. The complication of systemic or intracerebral haemorrhage was not observed in any of the groups. No complications occurred in the group receiving prehospital treatment during transfer to hospital.

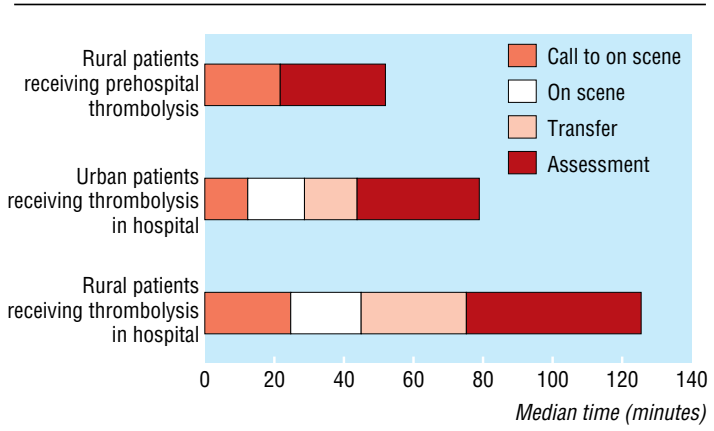

Fig 3 Composition of time delays-“call to needle" time. For values, see table

The call to needle time was shortest in the group of patients treated in the prehospital setting $(n=28)$. The median call to needle time for this group was 52 (95\% confidence interval 41 to 62 ) minutes, with an interquartile range of 39-71 minutes. Patients presenting from similar rural areas but treated in hospital $(n=43)$ had median call to needle times of 125 (104 to 140) minutes, with an interquartile range of $88-155$ minutes. The median call to needle time for patients presenting within $15 \mathrm{~km}$ of the base hospital for thrombolysis in hospital $(\mathrm{n}=107)$ was 80 (78 to 93$)$ minutes, with an interquartile range of 62-110 minutes. Administration of prehospital thrombolysis therefore resulted in a median time saving of 73 minutes over patients from rural areas $(\mathrm{P}<0.001$, Mann-Whitney $\mathrm{U}$ test) and 28 minutes over patients from urban areas ( $\mathrm{P}<0.001$, Mann-Whitney U test).

The table and figure 3 show the composition of time delay in terms of ambulance response time, time spent on scene, transfer time, and "door to needle time" (from arrival at the hospital to treatment). At the target call to needle time of 60 minutes, $64 \%(18 / 28)$ patients treated before arriving in hospital had received thrombolysis; this compares with $4 \%(2 / 43)$ in the cohort of similar patients treated in hospital. Figure 4 shows the cumulative distribution of time to the initiation of treatment 


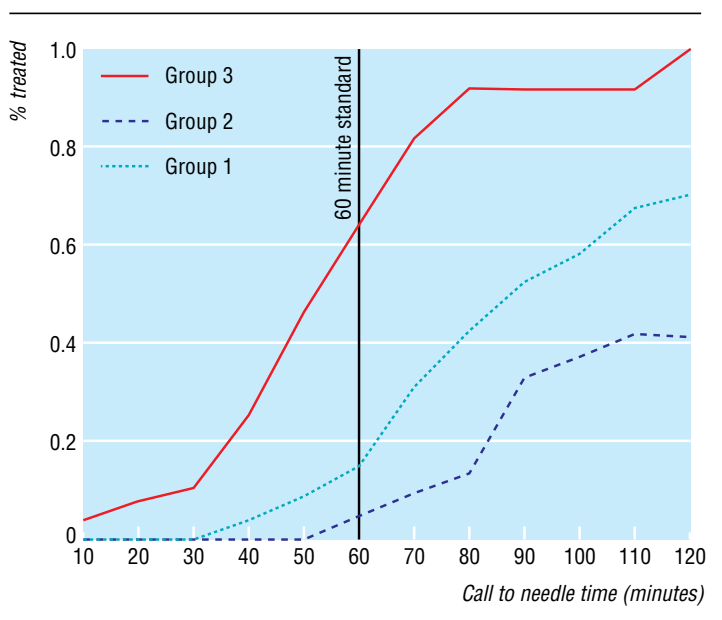

Fig 4 Cumulative distribution of call to needle time. Group 1 refers to patients from urban area receiving thrombolysis in hospital. Group 2 are patients from rural areas who received thrombolysis in hospital. Group 3 are patients from the study area who received prehospital thrombolysis

\section{Discussion}

A system of prehospital care based on a model delivered by paramedics, with support via a telemetry link, can meet the performance targets for early thrombolysis that the UK national service framework for coronary heart disease sets out. Thrombolytic treatment has been shown beyond doubt to reduce mortality in the context of an acute myocardial infarction. An overview of nine high quality randomised, placebo controlled, mortality endpoint trials, each containing more than 1000 patients, derived an average reduction in mortality of 18 per 1000 patients. Subgroup analysis of the larger trials confirms the hypothesis that early administration of thrombolytics results in the greatest benefits. Boersma et al evaluated 22 randomised trials to investigate the effect of delayed treatment on mortality. The non-linear relation shows a reduction in absolute and proportional mortality, with the greatest benefits within two hours of the onset of symptoms. By extrapolation, if thrombolytics could be delivered during this period up to an additional 80 patients per 1000 would be alive at one month compared with patients not given thrombolytics. ${ }^{3}$ Evidence from the Grampian region early anistreplase trial (GREAT) shows that the benefit in terms of morbidity and mortality is long lasting. Five year follow up of patients treated a median 101 minutes after the onset of symptoms indicated a greater mortality benefit in the period after one month than before. ${ }^{6}$

\section{Difficulties in meeting standards}

In recognition of the weight of evidence, national performance targets in the form of the national service framework have shifted emphasis towards early thrombolysis. ${ }^{5}$ In particular, standard six implies that thrombolysis should be administered within 60 minutes of calling for professional help. Call to needle time is selected as the most important measure as this best reflects the performance of healthcare systems in the delivery of thrombolytics. This standard will prove very difficult to meet. ${ }^{7}$ In rural areas where transfer times exceed 30 minutes, targets may be impossible to meet without developing systems for the delivery of thrombolysis in the community. ${ }^{8}$

\section{Other research}

Several published trials compare prehospital with in-hospital thrombolysis. ${ }^{9} 10^{11} 12$ Six of these meet the rigorous inclusion criteria for a systematic metaanalysis reported in 2000 by Morrison et al. ${ }^{4}$ All six trials when considered together favour prehospital thrombolysis and have not shown any significant hazards, with a reduction in absolute risk of all cause mortality in hospital of $2 \%$ per hour of earlier treatment. The trials illustrate the various models of prehospital delivery of thrombolysis, ranging from domiciliary thrombolysis given by general practition$\mathrm{ers}^{9}$ to hospital based mobile intensive care units staffed by emergency doctors. ${ }^{10}$ Prehospital thrombolysis delivered by paramedics with telemetry support has been shown to be successful in the myocardial infarction triage and intervention (MITI) trial. ${ }^{11}$

The early retavase-thrombolysis in myocardial infarction (ER-TIMI) 19 trial evaluated this model in 20 emergency medical systems in the United States. ${ }^{12}$ The study shows a median time saving of 32 minutes for the prehospital thrombolysis group, with electrocardiographic criteria for reperfusion achieved at an earlier stage compared with controls. No published data show this model in the United Kingdom.

\section{Advantages of new model}

In our context, with the imminent closure of the coronary care facility of a small district general hospital, prehospital thrombolysis offered a strategy to meet the needs of patients who are now exposed to longer journey times. We chose the paramedic based model in cooperation with the Scottish Ambulance Service as this offered a rapid start-up time. The period from agreement to delivery of service was less than six months. The model also has the advantage of cooperation, via a telemetry link between senior medical staff based in the accident and emergency department and the paramedic on the scene. This allows remote clinical decision support and essential backup for the paramedic in adopting a very different extended role. Our protocol required contact to be made between the accident and emergency department and the paramedic in each case. We collected no data on whether the initial diagnosis reached by the paramedic differed from the final consensus after discussion with the hospital based doctor.

\section{Additional lives saved}

In our study the only group to approach the call to needle standard of one hour were patients who were given thrombolytics in the community, with a median call to needle time of 52 minutes. Even patients presenting in the urban environment within $15 \mathrm{~km}$ of the hospital had a median call to needle time of 80 minutes despite achieving a favourable median door to needle time of 30 minutes. The group of patients from outside a $15 \mathrm{~km}$ radius who received thrombolytics in hospital were from areas with geographical and demographic similarities and had similar transfer times to the prehospital thrombolysis group. These patients had the longest call to needle times, with a median of 125 minutes. Given that our data show a time saving of more than one hour in the prehospital group, we might expect two extra lives 


\section{What is already known on this topic}

Early thrombolysis improves outcome in acute myocardial infarction

Patients from rural areas may be subject to long delays if thrombolysis is initiated only once they reach hospital

The deliver of thrombolytic agents by general practitioners in the prehospital setting has been shown to be safe and feasible and to reduce delay in treatment

\section{What this study adds}

A system of prehospital thrombolysis delivered by paramedics with hospital based decision support is effective in reducing call to needle time in patients from rural areas

saved per 100 patients treated. Benefits from prehospital thrombolysis have also been shown to include a reduction in overall morbidity. ${ }^{6}$

In all the groups, ambulance response time, defined as the time from calling for professional help to the arrival of an emergency ambulance, shows a marked difference between patients calling their general practitioner and those who dial 999. Although

\section{Corrections and clarifications}

As readers of the printed copy of the $B M J$ will have noticed, the recent "patient issue" of the BMJ (14 June) looked very different from our usual issues. Putting together our journal in this format (including using a different electronic production system) required even more care and attention than usual. We tried to avoid errors, but inevitably a few glitches occurred.

Patients'accounts of being removed from their general practitioner's list: qualitative study

We mixed up some references in this research paper by Tim Stokes and colleagues when we converted our usual style to the format required for this special issue (14 June, pp 1316-9). References 8-11 are correctly printed below. Also, the participants' quotes failed to be clearly differentiated from the main text, which made for difficult reading. In the authors' affiliation section, "practice" twice managed to gain a superfluous "a." All these errors occurred only in the printed version of the article. The revised references are:

8 Glaser BG, Strauss AL. The discovery of grounded theory strategies for qualitative research. Chicago: Aldine, 1967.

9 Goffman E. Asylums:essays on the social situation of mental patients and other inmates. London: Anchor Books, Doubleday, 1961.

10 Scambler G, Hopkins A. Being epileptic: coming to terms with stigma. Sociol Health $\mathrm{Ill}$ 1986;8:126-43

11 Goffman E. Stigma:notes on the management of spoiled identity. Harmondsworth: Penguin, 1968. Doctors'diagnosis

URLs continue to tax our powers of accuracy: we got two wrong (relating to multiple sclerosis) in the "Quick facts" section of this "Doctors' diagnosis" collection of three articles (14 June, p 1323-5). The website for the American Academy of Neurology is www.aan.com and for the International Multiple Sclerosis Support Foundation is www.msnews.org

\section{Perspectives}

We had not intended the title of Les Irwig's article to come out as "This added to my multiple myopia," but, rather inexplicably, it did (14 June, $\mathrm{p}$ 1336). In an attempt to keep to the style of the other titles in the "Perspectives" section, we had changed Les Irwig's perfectly appropriate suggestion of "Managing glaucoma: a patient's view," but what resulted didn't make sense. the contribution of general practitioners in this setting should not be underestimated in clear cut cases, the adoption of the "dual response" suggested by the British Heart Foundation might minimise this delay. ${ }^{13}$

Any system of prehospital thrombolysis requires a rapid response to calls about undifferentiated chest pain received from within the community. Over the 12 months of our study the accident and emergency department received 229 calls and effected thrombolysis in 28 patients. Although this ratio is broadly similar for patients receiving thrombolysis in hospital, it underlines the commitment and resources necessary to promote early treatment.

We thank R Chan, senior lecturer in cardiovascular epidemiology, for his help with the statistical analysis, Robert Colburn of the Scottish Ambulance Service for his help in establishing the project, and Steve Beedie, ambulance paramedic, for his help in collecting prehospital data.

Contributors: DKP designed the study and wrote the paper. KB and EMC collected the data and compiled the database. CGG was involved in the planning, implementation, and audit of the service. IG was responsible for paramedics' training and service development. GM and THP participated in validation of the data. SDP helped plan the service and revised the first draft of the paper. MCJ had the original idea for the provision and design of the service, participated in implementation and audit, and helped write the paper. MCJ is the guarantor.

Funding: Changes to services in Angus as outlined in this paper were approved and funded by the then Tayside Health Board on the basis that paramedic led thrombolysis services had already been implemented successfully in continental Europe. It was, however, a provision of the decision that the new service was audited. This paper presents the result of that audit.

Competing interests: None declared.

Ethical approval: The comparison of anonymised results from service provision was not thought to require formal ethical approval. This opinion was discussed with the chairman of the local ethics committee, and the view was endorsed.

1 Fibrinolytic Therapy Triallists' (FTT) Collaborative Group. Indications for fibrinolytic therapy in suspected acute myocardial infarction: collaborative overview of early mortality and major morbidity results from all randomised trials of more than 1000 patients. Lancet 1994;343:311-22.

2 Randomised trial of intravenous streptokinase, oral aspirin, both, or neither among 17,187 cases of suspected acute myocardial infarction: ISIS-2. ISIS-2 (Second International Study of Infarct Survival) Collaborative Group. Lancet 1988; 332: 349-60.

3 Boersma E, Maas ACP, Deckers JW, Simoons ML. Early thrombolytic treatment in acute myocardial infarction: reappraisal of the golden hour. Lancet 1996:348:771-5.

4 Morrison LJ, Verbeek PR, McDonald AC, Sawadsky BV, Cook DJ. Mortality and prehospital thrombolysis for acute myocardial infarction. A meta-analysis. JAMA 2000;283:2686-92

5 Department of Health. National service framework for coronary heart disease. London: DoH, 2000. www.doh.gov.uk/nsf/coronary.htm (accessed 6 Jun 2003).

6 Rawles JM. Quantification of the benefit of earlier thrombolytic therapy: five-year results of the Grampian region early anistreplase trial (GREAT) JAm Coll Cardiol 1997;30:1181-6.

7 Rawles JM. New standard of 60 minutes has been proposed but may be too rigorous. BMJ 1999;318:1554.

8 Rawles J, Sinclair C, Jennings K, Ritchie L, Waugh N. Call to needle times after acute myocardial infarction in urban and rural areas in North East Scotland: prospective observational study. BMJ 1998:317:576-8.

9 GREAT Group. Feasibility, safety and efficacy of domiciliary thrombolysis by general practitioners: Grampian region anistreplase trial: $B M$ J 1992;305:548-53.

10 Prehospital thrombolytic therapy in patients with suspected acute myocardial infarction. European Myocardial Infarction Project Group. NEngl J Med 1993;329:383-9.

11 Weaver WD, Cerqueira M, Hallstrom AP, Litwin PE, Martin JS, Kudenchuk PJ, et al. Prehospital-initiated vs. hospital-initiated thrombolytic therapy. The Myocardial Infarction Triage and Intervention Trial. JAMA 1993;270:1211-6.

12 Evaluation of the time saved by prehospital initiation of reteplase for ST-elevation myocardial infarction: results of the early retavasethrombolysis in myocardial infarction (ER-TIMI) 19 trial. J Am Coll Cardiol 2002;3:40:71-7.

13 Weston CFM, Penny WJ, Julian DG on behalf of the British Heart Foundation Working Group. Guidelines for the early management of patients with myocardial infarction. BMJ 1994;308:767-71.

(Accepted 9 June 2003) 